\title{
Probabilistic lifetime performance and structural capacity analysis of continuous reinforced concrete slab bridges
}

\author{
Zhicheng Gao ${ }^{1} \cdot$ Robert Y. Liang ${ }^{2} \cdot$ Anil K. Patnaik $^{1}$ (I)
}

Received: 3 November 2016/Accepted: 16 May 2017/Published online: 23 May 2017

(c) The Author(s) 2017. This article is an open access publication

\begin{abstract}
A reliability-based method was developed for predicting the initiation time and the probability of flexural failure for continuous slab bridges with load-induced cracks exposed to chloride environment resulting from deicing salts. A practical methodology was used for predicting the diffusion coefficient of chloride ingress into the pre-existing load-induced cracks in concrete. The reduction in the cross-sectional area of the reinforcement due to corrosion was included in the model. The proposed methodology accounts for uncertainties in the strength demand, structural capacity, and corrosion models, as well as uncertainties in environmental conditions, material properties, and structural geometry. All probabilistic data on uncertainties were estimated from the information contained in previous experimental and statistical studies. As an application of the proposed model, a three-span continuous slab bridge in Ohio is presented for demonstration of the developed methodology. A comparison of results clearly shows the importance of considering the effects of the load-induced cracks for correct prediction of the initiation of corrosion time and the critical time to maintain structural integrity.
\end{abstract}

Anil K. Patnaik

Patnaik@uakron.edu

Zhicheng Gao

zg8@zips.uakron.edu

Robert Y. Liang

rliang@udayton.edu

1 Department of Civil Engineering, University of Akron, Akron, OH 44325-3905, USA

2 Department of Civil and Environmental Engineering and Engineering Mechanics, University of Dayton, Dayton, $\mathrm{OH} 45469$, USA
Keywords Structural slab bridges · Probability of flexural failure $\cdot$ Corrosion initiation time $\cdot$ Load-induced cracking . Probabilistic analysis of slab bridges

\section{Introduction}

Chloride-induced corrosion of reinforcing steel in concrete is known to be one of the major causes of deterioration in reinforced concrete (RC) structures. Normally, concrete protects the embedded reinforcing steel against corrosion due to a thin layer of iron oxide $\left(\mathrm{Fe}_{2} \mathrm{O}_{3}\right)$ that forms on the steel surface and remains stable in the high alkaline environment of concrete pore solution. However, if an RC structure is exposed to chlorides, as is common when highway bridges are exposed to de-icing salts, chloride ions can penetrate the concrete cover and reach the surface of reinforcing bars. Because of the weather patterns in Northern United States, de-icing salts are used frequently during winter times on the riding surface of the highway bridges. From a review of the database of Special Application-Bridge Information System (SABIS) 2012, around $30 \%$ of the concrete bridges are constructed as continuous slab bridges (McClure and Daniell 2010). Thus, it is important to quantify the effect of the chloride-induced corrosion damage in terms of the capacity of concrete bridge superstructure. The capacity deterioration of the bridge superstructure is generally caused by the decrease in the cross-sectional area of the reinforcement. The general process of the reduction in the reinforcement bar diameter is shown in Fig. 1. The diameter of the reinforcement bar will not decrease until the corrosion initiation time $\left(T_{\mathrm{I}}\right)$ is reached. After reaching this point, the diameter will rapidly decrease until the structure reaches its critical failure condition. 


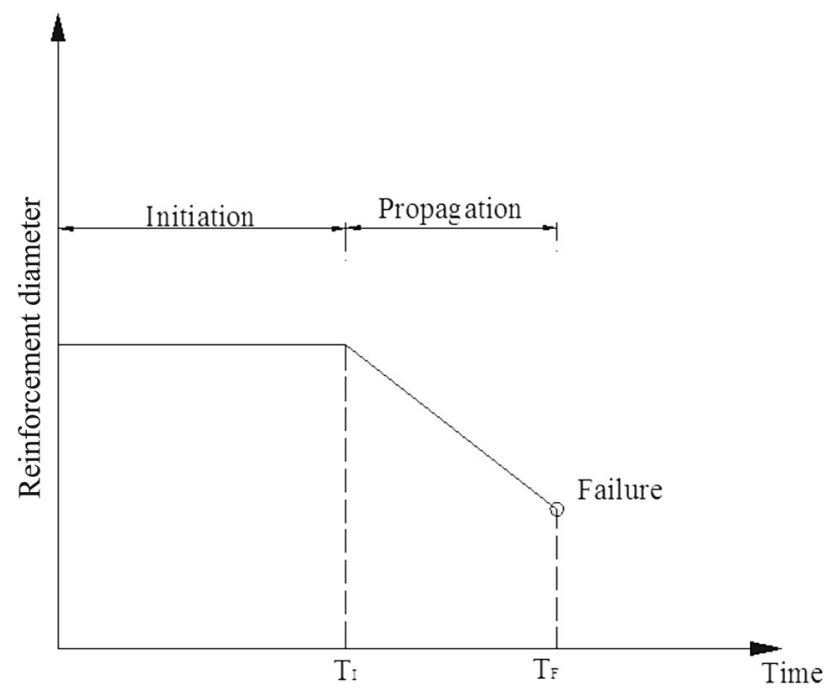

Fig. 1 Deterioration process for decrease of the reinforcement bar diameter

In the past, numerous models have been developed for 'perfect' and 'uncracked' concrete with Fick's second law (Crank 1975) used for predicting chloride-induced corrosion process of concrete reinforcement (Collepardi et al. 1970; Cady and Weyers 1984; Takewaka and Matsumoto 1988; Mangat and Molloy 1994; Maage et al. 1996; Bamforth 1999; Thomas and Bentz 2000; Kassir and Ghosn 2002; Maheswaran and Sanjayan 2004). However, concrete structures always function with some amount of cracking caused by service load, shrinkage, and other factors. The influence of penetration rate of chloride ions in concrete due to the presence of cracks and its effects on the corrosion process were investigated in some studies (Gérard and Marchand 2000; Boulfiza et al. 2003; Djerbi et al. 2008). However, most of the existing methods were developed within a deterministic framework. There is significant uncertainty associated with the factors related to the chloride ingress into concrete; it is more appropriate to use a probabilistic approach to predict the corrosion process in a concrete structure with service-load-induced cracks.

Considering the limitations of previous studies, the focus of this paper is on a probabilistic approach to predict the initiation time of corrosion process with load-induced cracks on the concrete surface. This approach is more reasonable than that of the deterministic methods or the models that do not consider the service-load-induced cracks. A suitable distribution is used to describe the initial corrosion time based on the consideration of the random environmental and structural variables. The difference between the initial corrosion time of cracked concrete and the initial corrosion time of uncracked concrete surface conditions is also compared.
For the ultimate strength of a bridge structure, American Association of State Highway and Transportation Officials (AASHTO) specifications (AASHTO 2012) provide limit state design equations. Design engineers use these deterministic equations with appropriate levels of safety. However, there are many uncertainty conditions of parameters and coefficients in the limit state equations that should be considered to obtain the probability of failure during the lifetime of a bridge. A probabilistic approach is a more accurate and reliable approach for predicting the strength limit state. After the initial corrosion process, the reinforcement cross-sectional area will decrease with time, which causes the strength capacity of the concrete structures to decrease rapidly. This study presents a probabilistic framework that can be used for forecasting the lifetime performance of existing reinforced concrete slab bridges with the deterioration process caused by corrosion damage. Furthermore, the capacity deterioration process of the bridge superstructures with corrosion damage under cracked and uncracked concrete surface conditions is also compared.

This paper comprises five sections. The first section describes a typical corrosion penetration model for 'perfect' and 'uncracked' concrete used in many earlier studies. The second section introduces a corrosion penetration model for load-induced cracked concrete and the corrosion initiation time calculation model. The loss of cross-sectional area of steel is computed for a given corrosion initiation time in the next section. The fourth section presents probabilistic models for the strength limit state of a concrete slab bridge subjected to corrosion. The appropriate limit state functions for the critical locations under the maximum bending moment of the slab concrete bridge are introduced in this section. The fifth section presents an illustrative example of the lifetime performance and the capacity deterioration during the service life of a typical three-span slab bridge.

\section{Corrosion penetration model for uncracked concrete}

\section{Classical chloride penetration model}

Chloride ions can enter the concrete by ionic diffusion due to the existing concentration gradient between the exposed surface and the pore solution of the cement matrix (i.e., the diffusion driving force) (Martín-Pérez et al. 2000). The classical diffusion process is often described by Fick's first law according to which, the transfer rate of chloride ions $J_{\mathrm{c}}$ through a plane perpendicular to the direction of diffusion is proportional to the concentration gradient $\partial C_{\mathrm{f}} / \partial x($ Crank 1975):

$J_{\mathrm{c}}=-D \frac{\partial C_{\mathrm{f}}}{\partial x}$, 
where $J_{\mathrm{c}}$ is the flux of chloride ions due to diffusion $(\mathrm{kg} /$ $\left.\mathrm{m}^{2} \mathrm{~s}\right) ; D$ is the diffusion coefficient $\left(\mathrm{m}^{2} / \mathrm{s}\right)$; and $C_{\mathrm{f}}$ is the free chloride concentration $\left(\mathrm{kg} / \mathrm{m}^{3}\right)$ at depth $x(m)$. The negative sign in Eq. (1) indicates that diffusion occurs in the opposite direction to that of increasing chloride concentration.

It is assumed that the diffusion coefficient does not depend on the concentration. The mass balance leads to an expression of Fick's second law for non-steady-state diffusion (Stanish et al. 1997):

$\frac{\partial C_{\mathrm{f}}}{\partial t}=-\frac{\partial J_{\mathrm{c}}}{\partial x}=-D \frac{\partial^{2} C_{\mathrm{f}}}{\partial x^{2}}$.

For the initial condition, where $C_{\mathrm{f}}(x>0, \quad t=0)$ is 0 and boundary condition $C_{\mathrm{f}}(x=0, \quad t>0)$ is a constant, a standard solution for Eq. (2) can be obtained as follows:

$C_{\mathrm{f}}(x, t)=C_{\mathrm{s}}^{\mathrm{f}}\left[1-\operatorname{erf}\left(\frac{x}{\sqrt{4 D_{\mathrm{a}} t}}\right)\right]$,

where $C_{\mathrm{f}}(x, t)$ is the free chloride concentration $\left(\mathrm{kg} / \mathrm{m}^{3}\right)$ at depth $x$ at time $t ; C_{\mathrm{s}}^{\mathrm{f}}$ is the surface content $\left(\mathrm{kg} / \mathrm{m}^{3}\right)$ of free chloride; erf is the Gaussian error function, erf $=\frac{2}{\sqrt{\pi}} \int_{0}^{x} \mathrm{e}^{-t^{2}} \mathrm{~d} t$; and $D_{\mathrm{a}}$ is the apparent diffusion coefficient $\left(\mathrm{m}^{2} / \mathrm{s}\right)$.

The diffusion coefficient is influenced by many factors. A probabilistic model of chloride-induced corrosion presented by DuraCrete (2000) was adopted in this study to predict the corrosion status of RC members. This model includes uncertainties of the structural parameters, environmental conditions, and model parameters. For design and prediction purposes, it is necessary to split the apparent chloride diffusion coefficient $D_{\mathrm{a}}$ into different measurable and quantifiable parameters in order to separate these effects from the material and the environment:

$D_{\mathrm{a}}=k_{\mathrm{e}} \cdot k_{\mathrm{t}} \cdot k_{\mathrm{c}} \cdot D_{\mathrm{o}}$,

where $k_{\mathrm{e}}$ is an environmental factor; $k_{\mathrm{t}}$ represents the influence of test methods to determine the empirical diffusion coefficient $D_{\mathrm{o}}$; and $k_{\mathrm{c}}$ is a parameter that accounts for the influence of curing.

Based on Eqs. (3) and (4), the final expression of the partial differential equation is:

$C_{\mathrm{f}}(x, t)=C_{\mathrm{s}}^{\mathrm{f}}\left[1-\operatorname{erf}\left(\frac{x}{\sqrt{4 k_{\mathrm{e}} \cdot k_{\mathrm{t}} \cdot k_{\mathrm{c}} \cdot D_{\mathrm{o}} t}}\right)\right]$.

\section{Surface content of free chloride}

The surface free chloride content is based on the environmental conditions where the bridge structure is located. Several environmental exposure classes are given in European concrete standard EN 206 (2000) and are summarized in Table 1. The different exposure environments will have different chloride ion contents in the outside environment of the structural components. A large amount of experimental data for surface chloride concentration due to the application of de-icing salts for individual bridges or groups of bridges have been published in the literature, and statistical distributions for the surface content have also been suggested by Duprat (2007). Measurement of $C_{\mathrm{f}}$ on existing structures has been made in a number of studies in USA and UK (Hutter and Donnelly 1977; Coggins and French 1990; Funahashi 1990; Roy et al. 1993; Bamforth 1996; Thoft-Christensen 1997; Zemajtis 1998; Wallbank 1989; Hoffman and Weyers 1994; Enright 1998; Enright and Frangopol 1998; Kirkpatrick and Weyers 2002). Table 2 summarizes the surface concentrations of total (acid-soluble) chloride $\left(\mathrm{kg} / \mathrm{m}^{3}\right)$ for structures that are presented in the available literature.

Chloride is typically found in concrete both in the free or uncombined form as well as in a combined form, where it is bound to cement hydration products through adsorption or chemical composition in the form of Friedel's salt. Although the free chloride is generally believed to be responsible for the initiation of corrosion, the chloride threshold value necessary to initiate corrosion of steel bars in concrete is mostly provided in terms of total chloride and only occasionally in terms of free chloride due to the difficulties in evaluating free chloride content in concrete. However, with the existence of a reasonably accurate relationship between free and total chlorides, this problem can be solved. Mohammed and Hamada (2003) proposed the relationship between water-soluble and acid-soluble chloride concentrations:

$C_{\mathrm{t}}=1.23 C_{\mathrm{f}}$,

where $C_{\mathrm{t}}$ is the total chloride content in concrete; and $C_{\mathrm{f}}$ is the free chloride content in concrete.

Akgül and Frangopol (2005a, b) suggested 15-year values to be around $4 \mathrm{~kg} / \mathrm{m}^{3}$ as the mean value of the surface chloride concentration levels for the decks of network of bridges in Colorado in their study. Kirkpatrick and Weyers (2002) collected field data from 129 concrete bridge decks built from 1968 to 1972 in Virginia, which appears to be the most comprehensive to date and location with a mean of $2.51 \mathrm{~kg} / \mathrm{m}^{3}$. Thus, based on the experimental data provided by Kirkpatrick and Weyers (2002) and Eq. (6), the surface concentration of free (water-soluble) chloride, $C_{\mathrm{f}}^{\mathrm{s}}$, for concrete structures exposed to deicing salts is modeled by a lognormal distribution with the mean of $2.04 \mathrm{~kg} / \mathrm{m}^{3}$ ( $0.51 \%$ by weight of the cement). For the coefficient of variation of $C_{\mathrm{f}}^{\mathrm{s}}$, the value reported by Enright (1998), which corresponds to 0.10, is used in this study. 
Table 1 Different class designation in EN 206 (2000)

\begin{tabular}{|c|c|c|c|c|c|}
\hline & $\begin{array}{l}\text { Class } \\
\text { designation }\end{array}$ & $\begin{array}{l}\text { Description of } \\
\text { environment }\end{array}$ & & $\begin{array}{l}\text { Class } \\
\text { designation }\end{array}$ & $\begin{array}{l}\text { Description of } \\
\text { environment }\end{array}$ \\
\hline $\begin{array}{l}\text { No risk of corrosion or } \\
\text { attack }\end{array}$ & X0 & Very dry & \multirow{3}{*}{$\begin{array}{l}\text { Corrosion induced by } \\
\text { chlorides other than } \\
\text { from sea water }\end{array}$} & XD1 & Moderate humidity \\
\hline \multirow{5}{*}{$\begin{array}{l}\text { Corrosion induced by } \\
\text { carbonation }\end{array}$} & $\mathrm{XC1}$ & Dry or permanently & & $\mathrm{XD} 2$ & Wet, rarely dry \\
\hline & $\mathrm{XC} 2$ & Wet, rarely dry & & XD3 & Cyclic wet and dry \\
\hline & $\mathrm{XC} 3$ & Moderate humidity & \multirow{3}{*}{$\begin{array}{l}\text { Corrosion induced by } \\
\text { chlorides from sea water }\end{array}$} & XS1 & Exposed to airborne salt \\
\hline & $\mathrm{XC} 4$ & Cyclic wet and dry & & XS2 & Permanently submerged \\
\hline & & & & XS3 & $\begin{array}{l}\text { Tidal, splash and spray } \\
\text { zones }\end{array}$ \\
\hline
\end{tabular}

Table 2 Surface concentration of total chloride from structure $\left(\mathrm{kg} / \mathrm{m}^{3}\right)$

\begin{tabular}{|c|c|c|c|c|}
\hline Researchers & Range & Mean & Coefficient of variation & Distribution \\
\hline Wallbank (1989) & $0.25-15$ & 6.5 & 0.7 & Lognormal \\
\hline Funahashi (1990) & $12.99-15.08$ & 14.15 & 0.08 & \\
\hline Coggins and French (1990) & $4.94-11.39$ & 7.42 & 0.4 & \\
\hline Thoft-Christensen et al. (1997) & \multicolumn{4}{|c|}{$2.13,2.41,2.69$ (no random information) } \\
\hline Zemajtis (1998) & & 4.46 & 0.5 & Gamma \\
\hline Hoffman and Weyers (1994) & $1.2-8.2$ & 3.5 & 0.5 & Lognormal \\
\hline Enright and Frangopol (1998) & $2.45-9.8$ & 5.63 & 0.1 & Lognormal \\
\hline Kirkpatrick et al. (2002) & $0.15-5.25$ & 2.51 & 0.68 & Gamma \\
\hline
\end{tabular}

\section{Threshold chloride concentration}

The value of the chloride concentration to initiate the corrosion process is referred to as the critical (threshold) chloride concentration $\left(C_{\mathrm{cr}}\right)$. Substantial amount of data have been published, discussing and presenting the chloride threshold levels (Coggins and French 1990; ThoftChristensen et al. 1997; Zemajtis 1998; West and Himne 1985; Kayyali and Haque 1995; Hussain et al. 1995; Manning et al. 1996; de Rincon et al. 2002; Alonso et al. 2000; Oh et al. 2003; ACI 2005; Mohammed and Hamada 2006). Determination of the chloride corrosion threshold can also be performed in a laboratory as opposed to the determination of surface chloride concentration, which normally requires field testing. A summary of chloride threshold levels published in the literature is shown in Table 3. The chloride threshold value necessary to initiate corrosion of steel bars in concrete is mostly provided in terms of total chlorides or acid-soluble $\mathrm{cl}^{-}$(\% by weight of cement or concrete).

As shown in Table 3, there is wide variation in the values obtained from different sources. One reason for this lack of agreement of these values is due to the chloride threshold being dependent on a large number of factors such as, cement type, supplementary cementing materials, $C_{3} A$ content of the cement, concrete mix proportions, water-to-cement ratio, property of reinforcing steel, proportion of water to soluble chlorides, age of concrete, carbonation, curing conditions, temperature, relative humidity and source of chloride penetration, among others. Because of the wide scatter of the observed values and also as a consequence of the lack of consistent statistical data, the lognormal distribution for the threshold chloride concentration was used in this study (Akgül and Frangopol 2005a, b). As an example, due to harsh climate conditions in Ohio, de-icing salts are used extensively during winter. A value corresponding to the condition of reinforced concrete exposed to chloride in service $(0.15 \%$ by the weight of cement) from ACI 318R-05 was used as the mean value and the coefficient of variation value used by Enright (1998). The coefficient of variation of the threshold chloride concentration of 0.15 was adopted.

\section{Diffusion coefficient}

The chloride diffusion coefficient $(D)$ of concrete has been widely studied (Thoft-Christensen et al. 1997; Zemajtis 1998; Andrade 1993, 1996; Bentz et al. 1996), which depends on a large number of factors. In general, these factors may be classified into two major categories: internal factors (e.g., cement composition, supplementary cementing materials, water-to-cement ratio $(w / c)$, the degree of hydration and aggregate size and grading) and external factors (such as relative humidity, temperature, and stress states). 
Table 3 Threshold chloride concentration as reported in the literature

\begin{tabular}{|c|c|c|c|}
\hline \multirow[t]{2}{*}{ Source } & \multirow[t]{2}{*}{ Conditions } & \multicolumn{2}{|c|}{ Threshold concentration $C_{\mathrm{cr}}$} \\
\hline & & $\begin{array}{l}\% \text { by weight of } \\
\text { cement }\end{array}$ & $\mathrm{kg} / \mathrm{m}^{3}$ \\
\hline West and Hime (1985) & Structures in a temperate climate & 0.04 & 1 \\
\hline Kayyali and Haque (1995) & $\begin{array}{l}\mathrm{cl}^{-} \text {added as admixture and considering different strength concretes with } \\
\text { different supplements }\end{array}$ & $0.03-0.18$ & $0.8-4.6$ \\
\hline Hussain et al. (1995) & Cement with different $C_{3} A$ content & $0.022-0.045$ & $0.56-1.16$ \\
\hline Coggins and French (1990) & De-icing salts for prestressed concrete bridges & $0.02-0.04$ & $0.45-0.92$ \\
\hline $\begin{array}{l}\text { Thoft-Christensen et al. } \\
\text { (1997) }\end{array}$ & $\begin{array}{l}\mathrm{cl}^{-} \text {from salty aggregates, salty mixing water, admixtures containing } \\
\text { chloride, seawater and de-icing salts in London, UK }\end{array}$ & 0.064 & 1.26 \\
\hline Zemajtis (1998) & $\begin{array}{l}\text { De-icing chemicals and the influence of the coastal region environment for } \\
\text { different concrete types }\end{array}$ & $0.007-0.16$ & $0.18-4.16$ \\
\hline Thompson et al. (2000) & Test results from $15 \% \mathrm{NaCl}$ solution & $0.11-0.19$ & $2.58-4.50$ \\
\hline de Rincon et al. (2002) & $\begin{array}{l}\text { Ordinary Portland cement (OPC), class C fly ash (FA) and silica fume (SF) } \\
\text { (exposure to air) }\end{array}$ & 0.062 & 1.6 \\
\hline Alonso et al. (2000) & Ordinary Portland cement, fly ash $(\mathrm{FA})(w / c=0.5)$ & $0.06-0.62$ & $1.56-16$ \\
\hline Oh et al. (2003) & $\mathrm{cl}^{-}$added as admixture & $0.01-0.02$ & $0.28-0.52$ \\
\hline \multirow[t]{4}{*}{ ACI 318R-05 (2005) } & Prestressed concrete & 0.009 & 0.24 \\
\hline & Reinforced concrete exposed to chloride in service & 0.023 & 0.6 \\
\hline & Reinforced concrete that will be dry or protected room moisture in service & 0.15 & 4 \\
\hline & All other reinforced constructions & 0.05 & 1.2 \\
\hline $\begin{array}{l}\text { Mohammed and Hamada } \\
\text { (2006) }\end{array}$ & Ordinary Portland cement exposure to air $(w / c=0.5)$ & $0.06-0.12$ & $1.6-3.2$ \\
\hline
\end{tabular}

Design diffusion coefficients are computed from the total chloride concentration curve of actual structures, which can be different from the experimental data obtained from the laboratory. The actual structures are subjected to non-uniformity in boundary chloride ion concentration, so that the diffusion coefficient in the structures is smaller than the experimental result with uniform boundary condition. In Thoft-Christensen et al. (1997), the reference diffusion coefficient was found to follow a normal distribution, and the mean and the standard deviation values varied with the water-to-cement ratio. Maeda et al. (2004) also developed empirical expressions for chloride diffusion coefficients of ordinary Portland cement with or without supplementary cementing materials. The empirical diffusion coefficient $D_{\mathrm{o}}$ $\left(\mathrm{cm}^{2} /\right.$ year $)$ can be calculated by using the following regression analysis equation (Swatekititham 2001):

$D_{\mathrm{o}}=3.15 \times 10^{7} \times 10^{4.5(w / c)^{2}+0.14(w / c)-8.47}$,

where $w / c$ is the water-to-cement ratio. The water-to-cement ratio is estimated from Bolomey's formula for Ordinary Portland Cement (OPC) concretes as given below:

$w / c=27 /\left(13.5+f_{\mathrm{c}}^{\prime}\right)$,

where $f_{c}^{\prime}$ is the concrete compressive strength determined from standard cylinder tests.

\section{Classical chloride penetration model for cracked concrete}

In reality, reinforced concrete components cannot remain 'uncracked' under service loading. There are many factors such as shrinkage of concrete, dead load, service load and so on that may cause surface cracks during the service life of a bridge. Consider an RC beam with a rectangular section with flexural cracks induced by service load (Fig. 2) with $w_{\mathrm{k}}$ as the crack width induced by service load and $s_{\mathrm{r}, \max }$ as the maximum crack spacing (Eurocode 2 2004). The diffusion mechanisms of chloride ingress into the cracked concrete can be modeled as follows.

Based on the partition of chloride diffusion through cracked concrete, as shown in Fig. 3, the diffusion coefficient of chloride penetration for cracked concrete, $D_{\mathrm{cc}}$, is expressed in the literature (Gérard and Marchand 2000; Djerbi et al. 2008) as:

$D_{\mathrm{cc}}=\frac{A D_{\mathrm{a}}+A_{\mathrm{cr}} D_{\mathrm{cr}}}{A+A_{\mathrm{cr}}}$

where $A$ is the area of uncracked concrete at the soffit of the beam which is exposed to chloride, $D_{\mathrm{cr}}$ is the value of the chloride diffusion coefficient inside the crack, and $A_{\mathrm{cr}}$ is the area of the crack at the soffit of the beam. 
Fig. 2 Illustration of crack width and crack spacing

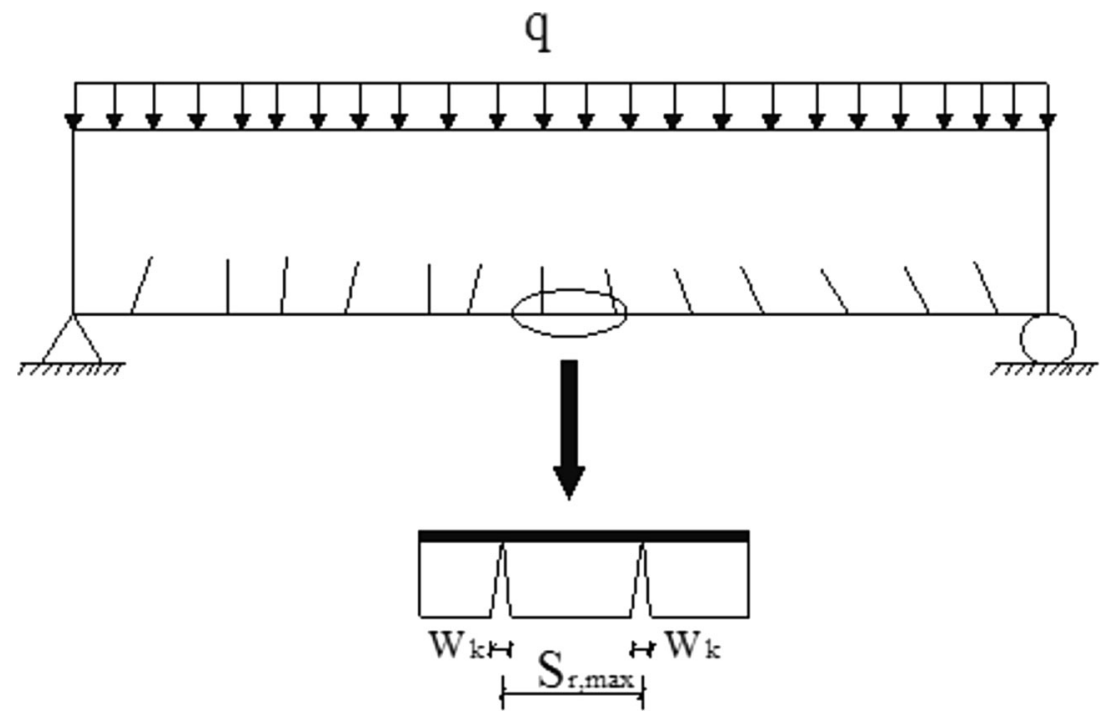

Fig. 3 Partition hypothesis of chloride diffusion through cracked concrete

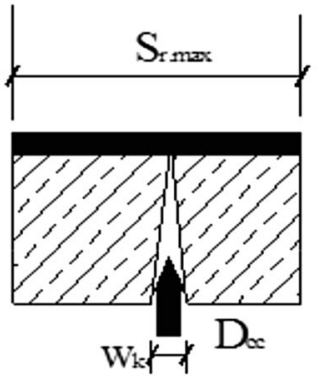

Cracked sample
For common rectangular section RC component, Eq. (9) may be rewritten as:

$$
\begin{aligned}
D_{\mathrm{cc}} & =\frac{b \cdot\left(s_{\mathrm{r}, \max }-w_{\mathrm{k}}\right) D_{\mathrm{a}}+b \cdot w_{\mathrm{k}} D_{\mathrm{cr}}}{b \cdot s_{\mathrm{r}, \max }} \\
& =D_{\mathrm{a}}+\frac{w_{\mathrm{k}}}{s_{\mathrm{r}, \max }}\left(D_{\mathrm{cr}}-D_{\mathrm{a}}\right) .
\end{aligned}
$$

Equation (10) is the proposed apparent diffusion coefficient for load-induced cracked concrete, where $D_{\mathrm{a}}$ is given in Eq. (4) and $D_{\mathrm{cr}}$ is obtained using the regression analysis of experimental data provided by Djerbi et al. (2008). The value of $D_{\text {cr }}$ is influenced by the crack width, but if the width is too small $(<30 \mu \mathrm{m})$ that $D_{\text {cr }}$ will not be used in calculating the diffusion coefficient of chloride penetration $\left(D_{\mathrm{cc}}\right)$. The empirical expressions are given as follows:

$D_{\mathrm{cr}}=\left\{\begin{array}{l}\left(0.16 w_{\mathrm{k}}-3\right) \times 10^{-10}, \quad 30 \mu \mathrm{m} \leq w_{\mathrm{k}} \leq 100 \mu \mathrm{m} \\ 13 \times 10^{-10}, \quad w_{\mathrm{k}}>100 \mu \mathrm{m}\end{array}\right.$.

According to Eurocode 2 (1992), $s_{\mathrm{r}, \max }$ and $w_{\mathrm{k}}$ are expressed by the following equations:

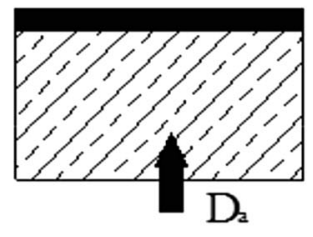

Uncracked sample
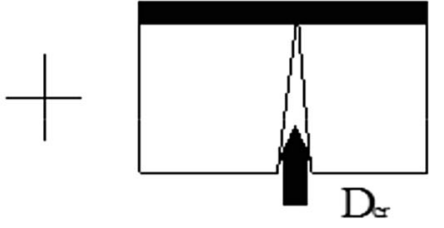

Crack $s_{\mathrm{r}, \max }=3.4 d_{\mathrm{c}}+0.425 k_{1} k_{2} \frac{d_{\mathrm{b}}}{\rho_{\mathrm{p}, \mathrm{eff}}}$,

$w_{\mathrm{k}}=s_{\mathrm{r}, \max } \frac{\sigma_{\mathrm{s}}-k_{\mathrm{tl}} \frac{f_{\mathrm{ctm}}}{\rho_{\mathrm{p}, \mathrm{eff}}}\left(1+\alpha_{\mathrm{e}} \rho_{\mathrm{p}, \mathrm{eff}}\right)}{E_{\mathrm{s}}}$,

where $d_{\mathrm{c}}$ is the cover depth; $k_{1}$ is a coefficient that takes into account the bond properties of the bonded reinforcement $\left(k_{1}=0.8\right.$ for high bond bars and $k_{1}=1.6$ for bars with an effectively plain surface); $k_{2}$ is a coefficient that takes into account the distribution of strain $\left(k_{2}=0.5\right.$ for bending and $k_{2}=1.0$ for pure tension); $d_{\mathrm{b}}$ is the bar diameter; $\rho_{\mathrm{p}, \text { eff }}=A_{\mathrm{s}} / A_{\mathrm{c}, \text { eff }}$, where $A_{\mathrm{c}, \text { eff }}$ is the effective tension area, i.e., $A_{\mathrm{c}, \text { eff }}$ is the area of concrete surrounding the tension reinforcement of depth $h_{\mathrm{c}, \text { eff }}$, where $h_{\mathrm{c}, \text { eff }}$ is the smallest of $2.5(h-d),(h-x) / 3$, or $h / 2$ (see Fig. 4 ); $\sigma_{\mathrm{s}}$ is the stress in the tension reinforcement assuming a cracked section; $k_{\mathrm{tl}}$ is the factor dependent on the duration of the load $\left(k_{\mathrm{t}}=0.6\right.$ for short-term loading and $k_{\mathrm{t}}=0.4$ for longterm loading); $\alpha_{\mathrm{E}}$ is the ratio $E_{\mathrm{s}} / E_{\mathrm{cm}} ; E_{\mathrm{s}}$ is the modulus of elasticity of steel; $E_{\mathrm{cm}}$ is the secant modulus of elasticity of concrete; and $f_{\text {ctm }}$ is mean value of axial tensile strength of 
Fig. 4 Definition of the effective tension area

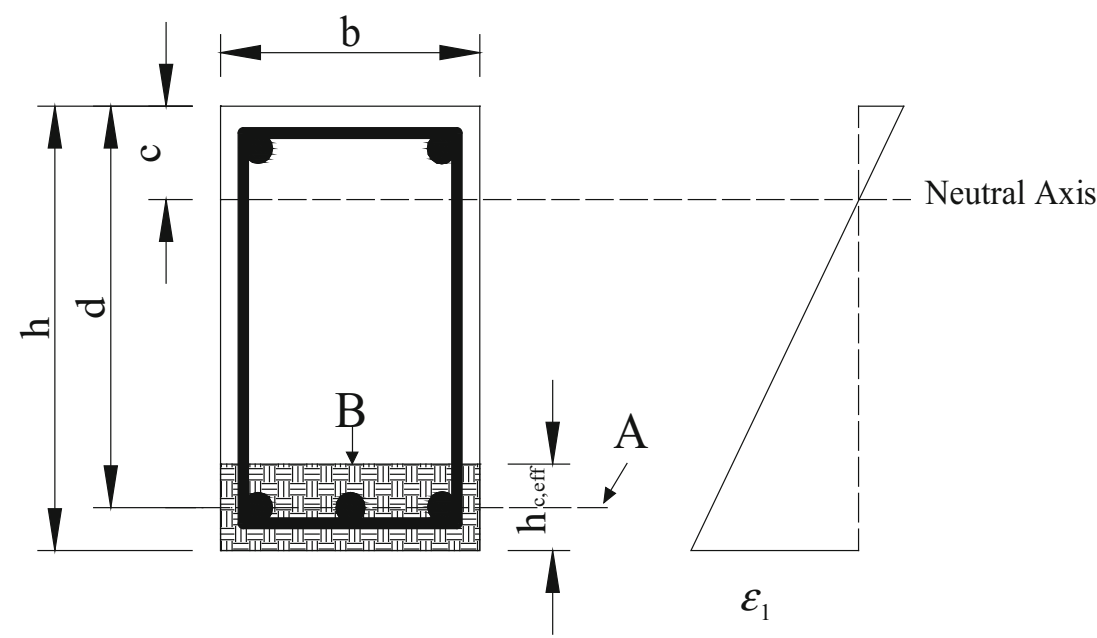

Typical section

\section{Strain Diagram}

A-level of steel centroid B-effective tension area concrete. The details of how $f_{\mathrm{ctm}}$ and $E_{\mathrm{cm}}$ change with the concrete strength can be found in Eurocode 2 (1992).

Replacing $D_{\mathrm{a}}$ with $D_{\text {cc }}$ in Eq. (5), the free chloride content at depth $x$ at time $t, C_{\mathrm{f}}(x, t)$, for cracked concrete can be obtained as:

$C_{\mathrm{f}}(x, t)=C_{\mathrm{f}}^{\mathrm{s}}\left[1-\operatorname{erf}\left(\frac{x}{\sqrt{4 \cdot D_{\mathrm{cc}} t}}\right)\right]$,

where $C_{\mathrm{f}}(x, t)$ is the free chloride concentration at depth $x$ at time $t ; C_{\mathrm{f}}^{\mathrm{s}}$ is the surface content of free chloride; and erf is the Gaussian error function, as used in Eq. (3).

\section{Corrosion initiation time model}

It is assumed that the corrosion process of the reinforcement starts when the chloride concentration of free chloride ions in concrete at the surface of reinforcing bars $\left(x=d_{\mathrm{c}}\right)$ reaches the threshold chloride concentration, which means $C_{\mathrm{f}}(x, t)$ reach the value of $C_{\mathrm{cr}}$. Since there is significant uncertainty associated with the threshold chloride concentration and the concentration of free chloride ions at the surface of reinforcing bars, it may be more appropriate to use a probabilistic approach to predict the time to corrosion initiation as well as the distribution of the corrosion initiation time. Equation (14) may be rearranged to calculate the corrosion initiation time when $t=T_{\text {in }}$ :

$T_{\text {in }}=X_{\mathrm{i}}\left[\frac{d_{\mathrm{c}}^{2}}{4 D_{\mathrm{cc}}}\left(\operatorname{erf}^{-1}\left(1-\frac{C_{\mathrm{cr}}}{C_{\mathrm{f}}^{\mathrm{s}}}\right)^{-2}\right)\right]^{1 / 1-n}$,

where $X_{\mathrm{i}}$ is a model uncertainty coefficient to account for the idealization implied by Fick's second law; $d_{c}$ is the reinforcement cover depth; and $C_{\mathrm{f}}^{\mathrm{s}}$ and $C_{\mathrm{cr}}$ are the surface content of free chloride and the critical (threshold) chloride content.

\section{Corrosion model for reinforcing steel}

Linear polarization technique is a non-destructive method for assessing the instantaneous corrosion current density. The method has been widely used in monitoring the corrosion of laboratory specimens and field structures (Clear 1992; Hope et al. 1985; Feliu et al. 1988, 1990). Stern and Geary (1957) showed that for a few millivolts above and below the corrosion potential, the polarization curve may be considered to be linear. Corrosion current density, often referred to as the corrosion rate, is directly proportional to the instantaneous rate of metal loss. Several devices, based on the linear polarization method, are presently used to determine the corrosion current density of steel in concrete.

Once the corrosion of the reinforcing steel begins, the diameter of steel providing resistance is gradually reduced through penetration of chloride ions. The time-dependent corrosion rate developed by $\mathrm{Vu}$ and Stewart (2000) is used to compute the loss of steel cross-sectional area over time. The corrosion current density at time $t$ is expressed as:

$i_{\text {corr }}(t)=0.85 i_{\text {corr }, \mathrm{o}}\left(t-T_{\text {in }}\right)^{-0.29}, \quad t \geq T_{\text {in }}$,

where $i_{\text {corr,o }}$ denotes the corrosion current density at the initiation of corrosion propagation:

$i_{\mathrm{corr}, \mathrm{o}}=\frac{37.5(1-w / c)^{-1.64}}{d_{\mathrm{c}}}$, 
Fig. 5 Flowchart of the proposed approach
Decide input deterministic variables and uncertainty variables and their distributions

Using corrosion penetration model for cracked concrete Eq. 14 and corrosion initiation time model Eq. 15 to get the corrosion initiation time distribution

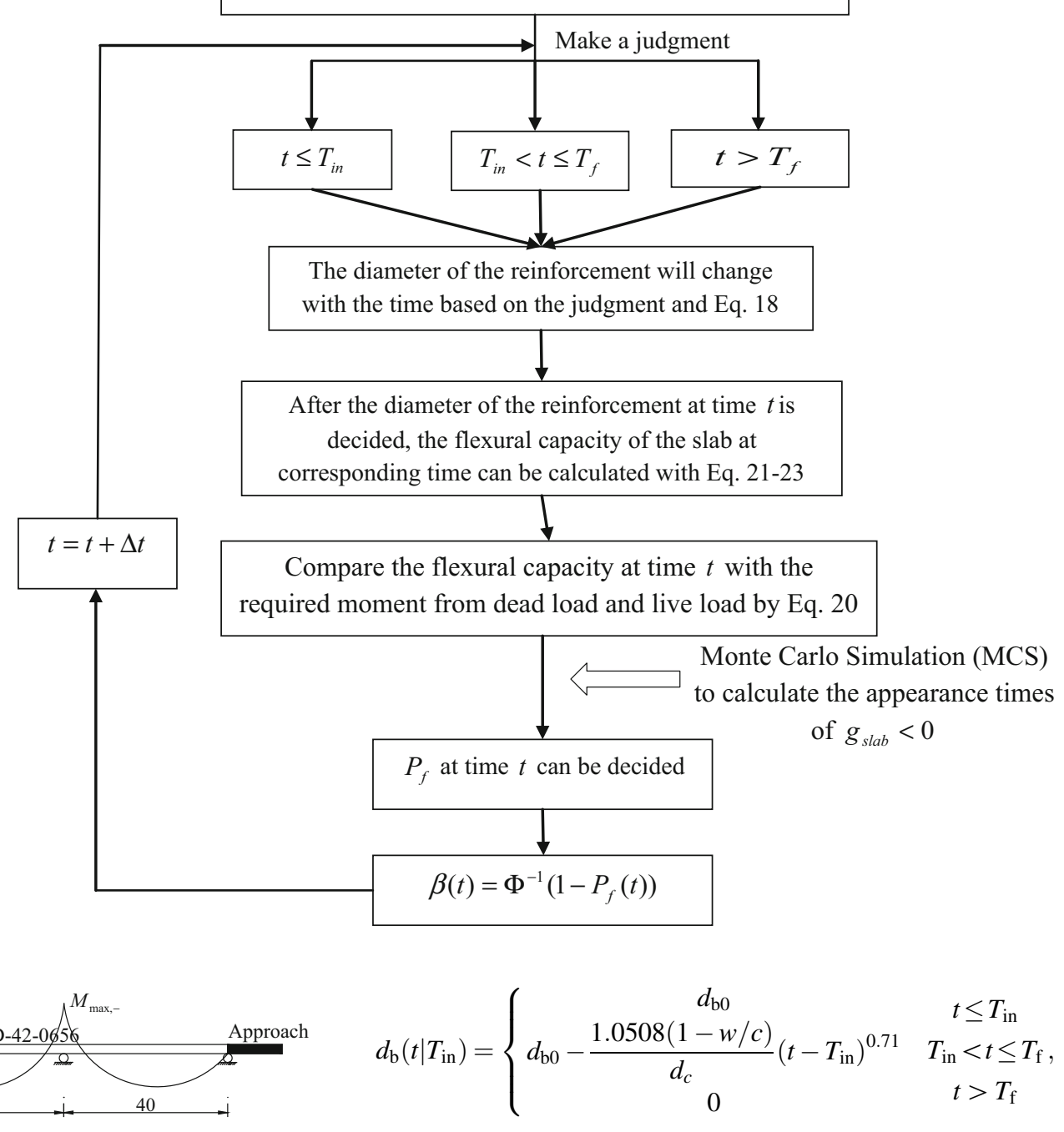

Fig. 6 The simplified side view and bending moment diagram for a three span RC slab bridge superstructure

where $w / c$ represents the water-to-cement ratio and $d_{\mathrm{c}}$ is the cover depth, which is the distance from the surface of the steel bar to the surface of the concrete. Note that according to Eq. (16), the corrosion rate diminishes with time because corrosion products formed around the bar will impede the diffusion of the iron ions.

Following Choe et al. (2007), after the corrosion process initiates, the diameter of the reinforcement is assumed to decrease over time. The variation of the diameter over time is expressed as: where $d_{\mathrm{b} 0}$ is the diameter of the reinforcement at time $t=0$, and $T_{\mathrm{f}}$ is the time when $d_{\mathrm{b}}\left(t \mid T_{\text {in }}\right)$, in theory, reaches zero, that is

$T_{\mathrm{f}}=T_{\mathrm{in}}+d_{\mathrm{bi}}\left\{d /\left[1.0508(1-w / c)^{-1.64}\right]\right\}^{1 / 0.71}$.

\section{Probabilistic analysis for RC bridges}

The prediction of the aging of concrete structures subjected to corrosion of reinforcement is complicated-not only because the related mechanical and chemical phenomena 


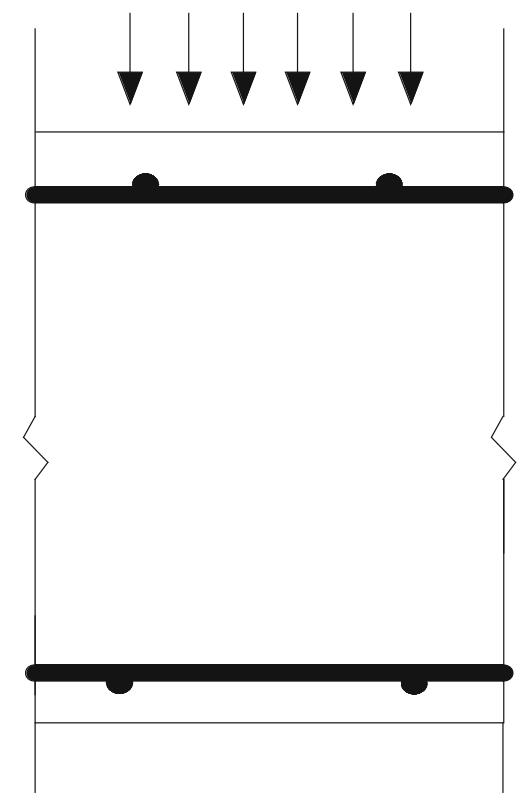

\section{Top surface at support}

Fig. 7 Chloride ion penetration into bridge slab

are complex but also because of their random nature. There is a high degree of uncertainty associated with the environmental parameters, physical properties of materials and loading.

Reliability analysis includes probabilistic information from all resistance and loading-related variables influencing the assessment process (not just point estimates). Reliability analysis provides a rational criterion for comparison of the likely consequences of decisions taken under uncertainty. Hence, risk-based approaches clearly define 'safety' or other performance criteria, and provide a measure by which safety, cost-effectiveness and other management considerations can be measured or compared. A structural deterioration life-cycle reliability (probabilistic) model is used herein to calculate the probabilities of structural failure.

\section{Limit state function for the capacity of a slab bridge}

For reinforced concrete slab bridges, the slab is typically designed as a rectangle beam with a unit width. Derivations of the limit state equation for flexural failure mode of slabs are presented herein.

In many states in the United States, the continuous slab bridges are the common type of bridges. For a continuous slab bridge, the positive moment near the midspan and the negative moment at the support location should be considered in design. However, because the concrete surface at the support location is the area that directly contacts the deicing salts, which are the sources of chloride, the top reinforcement at support location should consider the serious influence of corrosion damage. The limit state equation for flexure of a reinforced concrete slab at support location can be written in terms of negative flexural capacity of the section $M_{\mathrm{n}}^{-}$, dead load of structural components and nonstructural attachments moment $M_{\mathrm{DC}}$, dead load of wearing surface and utilities moment $M_{\mathrm{DW}}$, the moment due to live load from traffic including impact load moment $M_{\mathrm{TR}+\mathrm{IM}}$, and lane load moment $M_{\mathrm{LL}}$, as follows:

$g_{\text {slab }}=M_{\mathrm{n}}^{-}-\left(M_{\mathrm{DC}}+M_{\mathrm{DW}}+M_{\mathrm{TR}+\mathrm{IM}}+M_{\mathrm{LL}}\right)$.

Flexural capacity of the reinforcement in the concrete slab section is given by:

$M_{\mathrm{n}}^{-}=A_{\mathrm{s}}^{\mathrm{top}} f_{\mathrm{y}}\left(d_{\mathrm{s}}-\frac{a}{2}\right)$,

where $A_{\mathrm{s}}^{\text {top }}$ is the top reinforcement areas in the section over the support; $f_{\mathrm{y}}$ is the yield strength of reinforcing steel; $d_{\mathrm{s}}$ is distance from extreme compression fiber to the centroid of non-prestressed tensile reinforcement; $a$ is the corresponding depth of equivalent stress block, which is taken as:

$a=c \beta_{1}$,

$c=\frac{A_{\mathrm{s}}^{\mathrm{top}} f_{\mathrm{y}}}{0.85 \beta_{1} f_{\mathrm{c}}^{\prime} b}$,

where $\beta_{1}$ is the stress block factor which can be adopted from ACI 318R-05 (ACI 2005); $b$ is the unit width of design strip, which may be taken as 1 foot (or one meter) during the design process for the slab bridge.

Any structural analysis method can be used to calculate the positive and negative moment in the span and support locations in a continuous beam or slab. The Ohio Department of Transportation (ODOT) has developed various Excel files to be used as a standard to design and check the capacity of three-span continuous slab bridges with dif-

Table 4 Design details of example bridge

\begin{tabular}{llll}
\hline Top flexural reinforcement at support & Design concrete grade & Design steel grade & Design cover depth at top of the support \\
\hline \# 10 bars @ 6.25" & Concrete class HP $(4.5 \mathrm{ksi})$ & Grade $60(60 \mathrm{ksi})$ & $2.5 \mathrm{in}(63.5 \mathrm{~mm})$ \\
\hline
\end{tabular}


Table 5 Random variables

\begin{tabular}{|c|c|c|c|}
\hline Random variable & Distribution & Mean $(\mu)$ & Standard deviation $(\sigma)$ \\
\hline$d_{\mathrm{c}}^{\mathrm{top}}$ & Normal & $2.5 \mathrm{in}(63.5 \mathrm{~mm})$ & 0.005 in $(0.13 \mathrm{~mm})$ \\
\hline$f_{\mathrm{c}}^{\prime}$ & Lognormal & 4500 psi (31 Mpa) & 810 psi (5.6 Mpa) \\
\hline$E_{\mathrm{c}}=57,000 \sqrt{f_{\mathrm{c}}^{\prime}}($ elasticity of the concrete $)$ & Lognormal & 3824 ksi $\left(2.6 \times 10^{4} \mathrm{Mpa}\right)$ & $382 \mathrm{ksi}\left(2.6 \times 10^{3} \mathrm{Mpa}\right)$ \\
\hline$f_{\mathrm{ctm}}$ & Lognormal & 435 psi (3 Mpa) & 56 psi $(0.4 \mathrm{Mpa})$ \\
\hline$E_{\mathrm{cm}}$ & Lognormal & $4859 \mathrm{ksi}\left(3.4 \times 10^{4} \mathrm{Mpa}\right)$ & $486 \mathrm{ksi}\left(3.4 \times 10^{3} \mathrm{Mpa}\right)$ \\
\hline$d_{\mathrm{b}}$ & Lognormal (top) & 1.27 in $(32 \mathrm{~mm})$ & 0.038 in $(0.97 \mathrm{~mm})$ \\
\hline$f_{\mathrm{y}}$ & Lognormal & 60,000 psi (414 Mpa) & 6600 psi (45.5 Mpa) \\
\hline$E_{\mathrm{s}}$ & Lognormal & $30,458 \mathrm{ksi}\left(2.1 \times 10^{5} \mathrm{Mpa}\right)$ & $1828 \mathrm{ksi}\left(1.3 \times 10^{4} \mathrm{Mpa}\right)$ \\
\hline$\sigma_{\mathrm{s}}$ & Lognormal & $23.2 \mathrm{ksi}(160 \mathrm{Mpa})$ & 2.55 ksi (160 Mpa) \\
\hline$M_{\mathrm{DC}}$ & Lognormal (top) & 61.6 kips ft $(84.4$ kN m) & 15.4 kips ft (21.1 kN m) \\
\hline$M_{\mathrm{DW}}$ & Lognormal (top) & 12.3 kips ft $(16.8 \mathrm{kN} \mathrm{m})$ & 3.1 kips ft $(4.2 \mathrm{kN} \mathrm{m})$ \\
\hline$M_{\mathrm{TR}+\mathrm{IM}}$ & Lognormal (top) & 31 kips ft $(42 \mathrm{kN} \mathrm{m})$ & 7.8 kips ft $(11 \mathrm{kN} \mathrm{m})$ \\
\hline$M_{\mathrm{LL}}$ & Lognormal (top) & 12.4 kips ft $(17 \mathrm{kN} \mathrm{m})$ & 3.1 kips ft $(4.2 \mathrm{kN} \mathrm{m})$ \\
\hline$C_{\mathrm{f}}^{\mathrm{s}}(\%$ of the cement $)$ & Lognormal & 0.71 & 0.07 \\
\hline$C_{\mathrm{cr}}(\%$ of the cement $)$ & Lognormal & 0.15 & 0.02 \\
\hline$k_{\mathrm{e}}$ & Gamma & 0.924 & 0.155 \\
\hline$k_{\mathrm{t}}$ & Normal & 0.832 & 0.024 \\
\hline$n$ & Beta $(0-1)$ & 0.23 & 0.04 \\
\hline$X_{\mathrm{i}}$ & Lognormal & 1 & 0.05 \\
\hline
\end{tabular}

Top top location in the support

Table 6 Deterministic variables

\begin{tabular}{ll}
\hline Deterministic variable & Design value \\
\hline$k_{1}$ & 1.6 \\
$k_{2}$ & 0.5 \\
$k_{\mathrm{tl}}$ & 0.6 \\
$k_{\mathrm{c}}$ & 1 \\
\hline
\end{tabular}

ferent span widths. The design calculations provide the moment values of $M_{\mathrm{DC}}, M_{\mathrm{DW}}, M_{\mathrm{TR}+\mathrm{IM}}$ and $M_{\mathrm{LL}}$. The AASHTO HL93 load designation consists of a design truck plus design lane load or a design tandem plus design lane load, whichever produces the worst case scenario. A design truck is identical to the AASHTO HS20 load designation (AASHTO 2012). In view of a probabilistic approach, the probability of failure of the slab component of a concrete bridge at time $t$ can be determined by the following equation:

$$
\begin{aligned}
P(t) & =P\left[g_{\text {slab }} \leq 0\right] \\
& =P\left[M_{\mathrm{n}}^{-} \leq M_{\mathrm{DC}}+M_{\mathrm{DW}}+M_{\mathrm{TR}+\mathrm{IM}}+M_{\mathrm{LL}}\right] .
\end{aligned}
$$

In this study, the computation of the probability is based on the use of the Monte Carlo simulation (MCS) technique (Melchers 1999), which involves sampling at random to simulate artificially a large number of experiments and to interpret the result. In practice, there is a need for a more general definition of reliability that can express the probability of failure in terms of the coefficients of variation of various parameters that may or may not be normally distributed. One option is to express the reliability in terms of a reliability index, $\beta\left(\beta=\Phi^{-1}\left(1-P_{\mathrm{f}}\right)\right)$, which represents the probability of failure, $P_{\mathrm{f}}$. The flowchart of the proposed approach is shown in Fig. 5. The approach for bridge condition assessment is useful for quantifying the bridge deterioration during its service-life time based on the changing value of probability failure and reliability index with time.

\section{Bond strength failure}

The bond strength will decrease sharply with corrosion, which means at certain corrosion level the corroded reinforced concrete slab failure model will not be controlled only by flexural failure. This model presented in this paper does not consider the bond degradation or failure during the corrosion process and experimental work was done by considering the pull-out effect to eliminate the bond failure induced by corrosion (Gao et al. 2016a, b). However, that is not included in the scope of this model. 


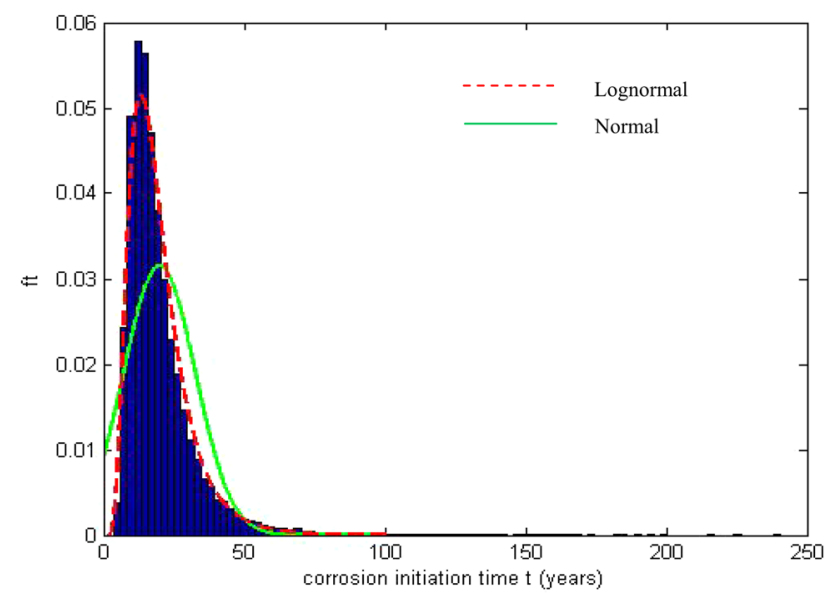

(a) Top reinforcement at the support with considering the effect of cracks

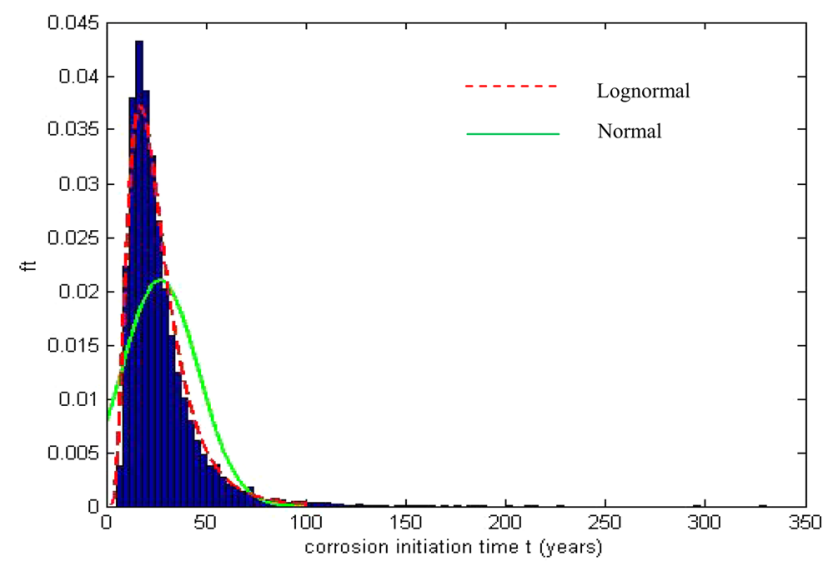

(b) Top reinforcement at the support without considering the effect of cracks

Fig. 8 The results for the corrosion initial time

\section{Application}

The developed methodology is applied to a three-span continuous concrete slab bridge with a reinforced concrete substructure that spans State Route 60 in Ashland County, Ohio. This slab bridge, designated as bridge number ASD42-0656 and built in 1955, has three spans of 40-50-40 feet (12.2-15.2-12.2 m). This bridge was rebuilt in 2000 with the slab replaced at that time. The actual slab thick- ness is 24 in $(610 \mathrm{~mm})$ and the unit width was taken as 12 in $(305 \mathrm{~mm})$. The simplified bridge side view and bending moment diagram under uniform loading for a three-span continuous slab bridge superstructure is shown in Fig. 6. The damage scenario (i.e., runoff) for chloride ion penetration into the slab over the supports is shown in Fig. 7. The design details of flexural reinforcement and concrete cover at the support locations are listed in Table 4.

The statistical and deterministic parameters for structure and corrosion variables considered in this example are listed in Tables 5 and 6. Here, all the random variables are assumed as mutually independent since there is no direct relationship among them. The top reinforcement at the critical support locations, as determined using the deterministic design procedures based on ODOT's standard practice, for predicting of probability of failure is analyzed.

Firstly, the results of the initial corrosion time with or without considering the effects of cracking for each critical location can be calculated and are shown in Fig. 8. Minitab was used to check the distribution fitting of the results data. The fitting results are shown in Table 7.

Based on Fig. 8 and Table 7, it can be seen that the distributions of the corrosion initial time for top reinforcement at the supports are more similar to a lognormal distribution. The results for the two scenarios (with and without considering the effects of cracking) at the critical location are shown in Table 8 .

In this study, the corrosion initial time is chosen as the mean value for each critical location. When the corrosion initial time is reached, the capacity deterioration for the structure begins. The reinforcement area for each critical location will decrease with the process of corrosion damage. After a few years, if the corrosion process continues without interruptions, the flexural capacity of the slab (bridge superstructure) will become inadequate to resist the dead load moment and live load moment, which means the structure will theoretically fail under the service load as defined in the structural design.

In this study, uncertainties about the structure properties and chloride penetration model are considered. Thus, the probability of failure and the reliability index at a certain time $t$ of the lifetime of the bridge can be predicted with the Monte Carlo simulation. The typical performance levels,

Table 7 Minitab fitting results

\begin{tabular}{lllll}
\hline Concrete condition & Location & Distribution & Anderson-Darling test (AD value) & Ryan-Joiner (RJ value) \\
\hline Cracked concrete & Top reinforcement at support & Normal fit & 407 & 0.901 \\
& & Lognormal fit & 32.4 & 0.992 \\
Uncracked concrete & \multirow{2}{*}{ Top reinforcement at support } & Normal fit & 572 & 0.821 \\
& & Lognormal fit & 42.9 & 0.989
\end{tabular}

The smaller AD value, the data will be more like normal distribution; the closer to 1 for RJ value, the data will be more like normal distribution 
Table 8 Results for three critical locations with or without considering the effects of cracks

\begin{tabular}{|c|c|c|c|c|c|}
\hline \multirow[t]{3}{*}{ Location } & \multicolumn{4}{|c|}{$T_{\text {in }}$ (years) } & \multirow[t]{3}{*}{ Mean value decrease percentage } \\
\hline & \multicolumn{2}{|c|}{$\begin{array}{l}\text { Without considering the effect of } \\
\text { cracks }\end{array}$} & \multicolumn{2}{|c|}{$\begin{array}{l}\text { With considering the effect of } \\
\text { cracks }\end{array}$} & \\
\hline & Mean & Standard deviation & Mean & Standard deviation & \\
\hline Top reinforcement at the support & 27 & 18.9 & 20 & 12.6 & $26 \%$ \\
\hline
\end{tabular}

Table 9 Example values for $\beta$ and $P_{\mathrm{f}}$ Source: Based on Corps of Engineers (1997)

\begin{tabular}{lll}
\hline Performance level & Reliability index, $\beta$ & Probability, $P_{\mathrm{f}}=P\left(g_{\text {slab }}<0\right)$ \\
\hline High & 5.0 & $2.871 \times 10^{-7}$ \\
Good & 4.0 & $3.169 \times 10^{-5}$ \\
Above average & 3.0 & 0.00135 \\
Below average & 2.5 & 0.00621 \\
Poor & 2.0 & 0.02275 \\
Unsatisfactory & 1.5 & 0.06681 \\
Hazardous & 1.0 & 0.15866 \\
\hline
\end{tabular}

Fig. 9 Reliability index variation of the structural capacity with time

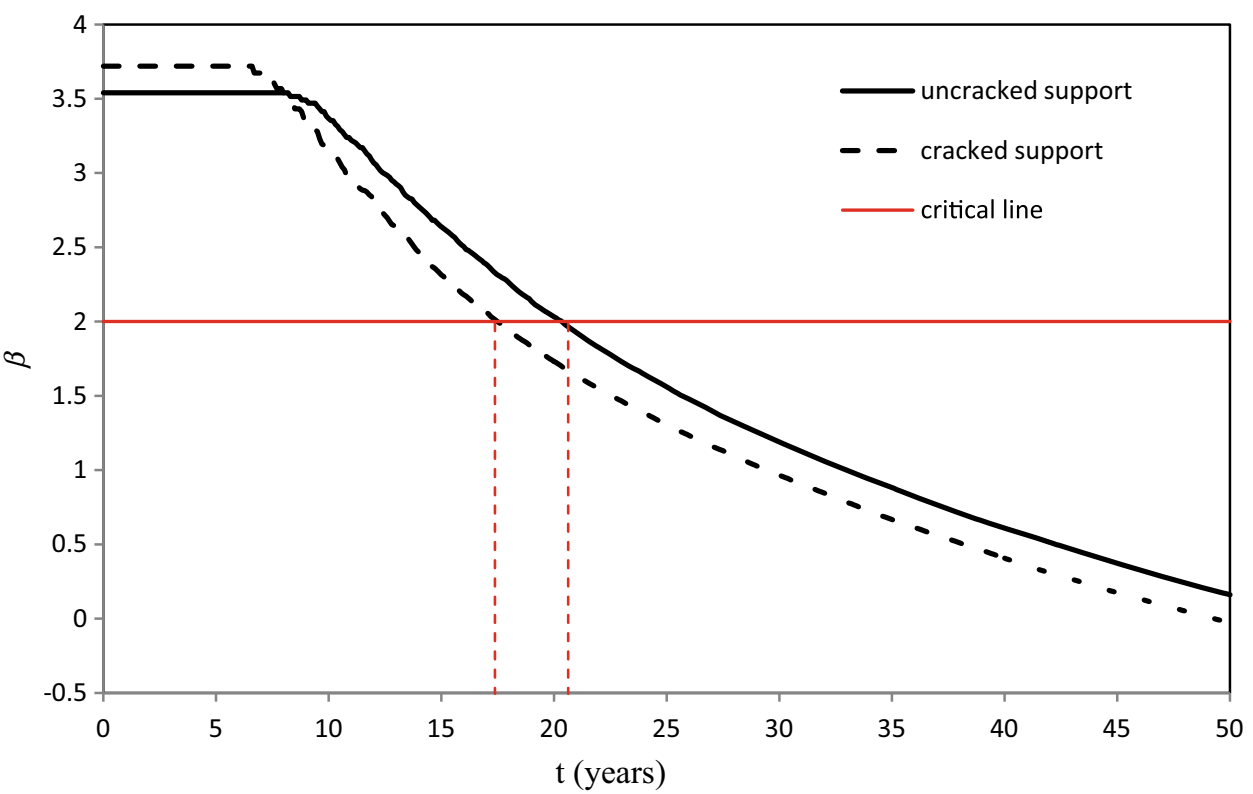

Table 10 Critical time of the critical structural capacity of the slab bridge

\begin{tabular}{lllll}
\hline Critical locations & Critical time (years) & Decrease percentage \\
\cline { 2 - 4 } & Without load-induced cracks & With load-induced cracks & \multirow{2}{*}{$15 \%$} \\
\hline Top reinforcement at the support & 20.5 & 17.5 & $15 \%$ \\
\hline
\end{tabular}

based on the values found in a US Army Corps of Engineers report (Corps of Engineers 1997), are shown in Table 9 .
Figure 9 shows the results for the reliability index variation with time for the critical locations at the support. If the critical reliability index is 2 (the structure condition 
is poor), the critical conditions for the structural capacity of the slab bridge at support locations can be determined and are shown in Table 10. As can be observed from this table, there is nearly a $15 \%$ decrease in the critical time when one considers the effect of the load-induced cracks in the application example. These results clearly demonstrate that prediction of the structural capacity critical time without considering the effect of load-induced cracks on the chloride ingress into concrete can lead to an overestimation of structural capacity.

\section{Conclusions}

From the present study, the following conclusions can be drawn:

- The initial corrosion time calculated by random environment and structure variables is not a deterministic value, but a random variable. Based on the statistical analysis, the initial corrosion time at the top surface over the supports is more likely to follow a lognormal distribution.

- Based on the probabilistic analysis for the reinforcement at the top of the support location, the initial corrosion time will be $26 \%$ earlier when considering a load-induced cracking than the time obtained for the condition that does not consider a load-induced crack.

- Probabilistic analysis is used in this paper to estimate the time-varied reliability index of the structure capacity at critical locations in the slab bridge such as at support location (negative moment). The reliability index $\beta=2$ (structure condition is poor) is chosen as the critical value in this paper. The critical time for the critical locations of the slab bridge will be reached around 20 years. Based on the analysis, the results from the models of 'uncracked' concrete underestimate the critical condition time when compared with the results from the probabilistic model presented in this paper that considers the influence of the load-induced cracks. The critical condition will be reached $15 \%$ earlier for the 'cracked' concrete condition than for the 'uncracked' concrete condition.

- The load-induced cracks will significantly influence the accuracy of prediction of the capacity variation subject to reinforcement corrosion damage. This is important for maintenance agencies to consider when making decisions regarding bridge repair scheduling, so that repairs can be completed in time to ensure that the superstructure of the bridge can be in service during its service life as originally designed.
Acknowledgements This work was associated with the National Corrosion Center (NCERCAMP) at The University of Akron and the DoD Technical Corrosion Collaboration (TCC), U.S. DoD Office of Corrosion Policy and Oversight. The research is administered by the U.S. Construction Engineering Research Laboratory under agreement number FY12 W9132T-11-C-0035.

Open Access This article is distributed under the terms of the Creative Commons Attribution 4.0 International License (http://crea tivecommons.org/licenses/by/4.0/), which permits unrestricted use, distribution, and reproduction in any medium, provided you give appropriate credit to the original author(s) and the source, provide a link to the Creative Commons license, and indicate if changes were made.

\section{References}

ACI (2005) Building code requirements for structural concrete (ACI 318-05) and commentary (ACI 318R-05). American Concrete Institute, Farmington Hills

Akgül F, Frangopol MD (2005a) Lifetime performance analysis of existing reinforced concrete bridges. I: theory. J Infrastruct Syst 11(2):122-128

Akgül F, Frangopol MD (2005b) Lifetime performance analysis of existing reinforced concrete bridges. II: application. J Infrastruct Syst 11(2):129-141

Alonso C, Andrade C, Castellote M, Castro P (2000) Chloride threshold values to depassivate reinforcing bars embedded in a standardized OPC mortar. Cem Concr Res 30(7):1047-1055

American Association of State Highway and Transportation Officials (AASHTO) (2012) Standard specifications for highway bridges. American Association of State Highway and Transportation Officials, Washington, D.C

Andrade C (1993) Calculation of chloride diffusion coefficients in concrete from ionic migration measurements. Cem Concr Res 23:724

Andrade C, Castellote M, Cervigon D, Alonso C (1996) Influence of external concentration and testing time on chloride diffusion coefficient values of steady state and nonsteady state migration experiments. In: Page CL, Bamforth PB, Figg JW (eds) Corrosion of reinforcement in concrete construction. SCI, The Royal Society of Chemistry, Cambridge, pp 76-87

Bamforth PB (1996) Definition of exposure classes and concrete mix requirements for chloride contaminated environments. In: Page CL, Bamforth PB, Figg JW (eds) Corrosion of reinforcement in concrete construction. SCI, The Royal Society of Chemistry, Cambridge, pp 176-188

Bamforth PB (1999) The derivation of input data for modeling chloride ingress from eight year U.K. coastal exposure trials. Mag Concr Res 51(2):89-96

Bentz DP, Clifton J, Snyder K (1996) A prototype computer integrated knowledge system: predicting service life of chloride exposed steel-reinforced concrete. Concr Int 18(12):42-47

Boulfiza M, Sakai K, Banthia N, Yoshida H (2003) Prediction of chloride ions ingress in uncracked and cracked concrete. ACI Mater J 100(1):38-48

Cady PD, Weyers RE (1984) Deterioration rates of concrete bridge decks. ASCE J Transp Eng 110(1):34-44

Choe D, Gardoni P, Rosowsky D, Haukaas T (2007) Probabilistic capacity models and seismic fragility estimates for RC columns subject to corrosion. Reliab Eng Syst Saf 93:383-393

Clear KC (1992) Measuring rate of corrosion of steel in field concrete structures. Transp Res Rec 1211:28-38 
Coggins FB, French CW (1990) Chloride ion distribution in twentyyear-old prestressed bridge girders. ACI Mater J 87(5):479-488

Collepardi M, Marcialis A, Turriziani R (1970) The kinetics of chloride ions penetration in concrete. Il Cemento 4:157-164

Crank J (1975) The mathematics of diffusion, 2nd edn. Oxford University Press, London

Corps of Engineers (1997) Engineering and design introduction to probability and reliability methods for use in geotechnical engineering. Engineering technical letter NO. 1110-2-547. Department of Army, Washington, D.C.

de Rincon O, Hernandez Y, Fernandez R, Morales M, Inciarte K (2002) Comparison between chloride ion threshold and electrochemical measurements for reinforcement corrosion. In: Proceedings of the 3rd RILEM international workshop testing and modelling the chloride ingress into concrete, Madrid

Djerbi A, Bonnet S, Khelidj A, Baroghel-Bouny V (2008) Influence of traversing crack on chloride diffusion into concrete. Cem Concr Res 38(6):877-883

Duprat F (2007) Reliability of RC beams under chloride-ingress. Constr Build Mater 21(8):1605-1616

DuraCrete (2000) Statistical quantification of the variables in the limit state functions. The European Union Brite EuRam 3 contract BRPR-CT95-0132 project BE95-1347 report no BE95-1347/R7

EN 206 (2000) Concrete-part 1: specification, performance, production and conformity

Enright M (1998) Time variant reliability of reinforced concrete bridges under environmental attack. PhD thesis, Univ. of Colorado, Boulder

Enright MP, Frangopol DM (1998) Probabilistic analysis of resistance degradation of reinforced concrete bridge beams under corrosion. Eng Struct 20(11):960-971

Eurocode 2 (2004) Design of concrete structures-part 1-1: general rules and rules for buildings (EN 1992-1-1). European Committee for Standardization: British Standards Institution

Feliu S, Gonzales JA, Andrade C, Feliu V (1988) Determination of polarization resistance in reinforced concrete slabs. Corrosion 44(10):761-765

Feliu S, Gonzales JA, Feliu S Jr, Andrade C (1990) Confinement of electric signal for in situ measurement of polarization resistance in reinforced concrete. ACI Mater J 87:457-460

Funahashi M (1990) Predicting corrosion-free surface life of a concrete structure in a chloride environment. ACI Mater $\mathrm{J}$ 87(6):581

Gao ZC, Liang RY, Patnaik AK (2016a) Effects of sustained loading and pre-existing cracks on corrosion behavior of reinforced concrete slabs. Constr Build Mater 12:776-778

Gao ZC, Liang RY, Patnaik AK (2016b) Mass loss and capacity loss of reinforced concrete slabs with and without polypropylene fibers corroded with pre-existing cracks and sustained loading. NACE corrosion risk management conference, Huston

Gérard B, Marchand J (2000) Influence of cracking on the diffusion properties of cement-based materials part I: influence of continuous cracks on the steady-state regime. Cem Concr Res 30(1):37-43

Hoffman PC, Weyers RE (1994) Predicting critical chloride levels in concrete bridge decks. In: Shuëller GI, Shinozuka M, Yao JTP (eds) Structural safety \& reliability, proceedings of ICOSSAR'93. Balkema, Innsbruck, pp 957-959

Hope BB, Ip AK, Manning D (1985) Corrosion and electrical impedance in concrete. Cem Concr Res 15:525-534

Hussain SE, Rasheeduzzafar A, Al-Musallam AS (1995) Al-Gahtani. Factors affecting threshold chloride for reinforcement corrosion in concrete, cement and concrete research 25(7):1540-1555

Hutter W, Donnelly DE (1977) Rate of deterioration of concrete bridge decks in Colorado. Final rep. no. CDOH-P\&R-R-77-6, Colorado Division of Highways, Denver, Colorado
Kassir MK, Ghosn M (2002) Chloride-induced corrosion of reinforced concrete bridge decks. Cem Concr Res 32(1):139-143

Kayyali OA, Haque MN (1995) The ratio of $\mathrm{Cl}-/ \mathrm{OH}-$ in chloride contaminated concrete-a most important criterion. Mag Concr Res 47:235-242

Kirkpatrick TJ, Weyers RE, Sprinkel MM, Anderson-Cook CM (2002) Impact of specification changes on chloride-induced corrosion service life of bridge decks. Cem Concr Res 32(8):1189-1197

Maage M, Helland S, Pouken E, Vennesland Ø, Carlsen J (1996) Service life prediction of existing concrete structures exposed to marine environment. ACI Mater J 93(6):602-608

Maeda S, Takewaka K, Yamaguchi T (2004) Quantification of chloride diffusion process into concrete under marine environment. Proc Japan Soc Civ Eng 760(63):109-120

Maheswaran T, Sanjayan JG (2004) A semi-closed-form solution for chloride diffusion in concrete with time-varying parameters. Mag Concr Res 56(6):359-366

Mangat P, Molloy B (1994) Prediction of long term chloride concentration in concrete. Mater Struct 27:338-346

Manning DG, Ip AKC (1996) Corrosion performance of chloride bearing aggregates in concrete. In: Page CL, Bamforth PB, Figg JW (eds) Corrosion of reinforcement in concrete construction. SCI, The Royal Society of Chemistry, Cambridge, pp 55-66

Martín-Pérez B, Zibara H, Hooton RD, Thomas MDA (2000) Numerical solution of mass transport equations in concrete structures. Cem Concr Res 30(8):1251-1264

McClure S, Daniell K (2010) Development of user-friendly software application for extracting information from national bridge inventory source files. J Transp Res Board 2202:137-147

Melchers RE (1999) Structural reliability analysis and prediction. Wiley, Chichester

Mohammed TU, Hamada H (2003) Relationship between free chloride and total chloride contents in concrete. Cem Concr Res 33(9):1487-1490

Mohammed TU, Hamada H (2006) Corrosion of steel bars in concrete with various steel surface conditions. ACI Mater J 103:233-242

Oh BH, Jang SY, Shin YS (2003) Experimental investigation of the threshold chloride concentration for corrosion initiation in reinforced concrete structures. Mag Concr Res 55(2):117-124

Roy SK, Chye LK, Nothwood DO (1993) Chloride ingress in concrete as measured by field exposure tests in the atmospheric, tidal and submerged zones of a tropical marine environment. Cem Concr Res 23:1289

Stanish KD, Hooton RD, Thomas MDA (1997) Testing the chloride penetration resistance of concrete: a literature review. FHWA Contract DTFH61-97-R-00022. Dept. of Civil Engineering, Univ. of Toronto, Toronto

Stern M, Geary AL (1957) Electrochemical polarization no. 1: theoretical analysis of the shape of polarization curve. J Electrochem Soc 104:56-63

Swatekititham S (2001) Chloride diffusivity of self-compacting concrete with limestone powder. Master dissertation, Kochi University of Technology, Japan

Takewaka K, Matsumoto S (1988) Quality and cover thickness of concrete based on the estimation of chloride penetration in marine environments. In: Malhotra VM (ed) Concrete in marine environment, Sp-109. American Concrete Institute, Detroit, pp 381-400

Thoft-Christensen P, Jensen FM, Middleton CR, Blackmore A (1997) Assessment of the reliability of concrete slab bridges. In: Frangopol DM, Corotis RB, Rackwitz R (eds) Reliability and optimization of structural systems. Elsevier, New York, pp 321-328

Thomas MDA, Bentz EC (2000) Life-365: computer program for predicting the service life and life-cycle costs of reinforced 
concrete exposed to chlorides. American Concrete Institute, Detroit

Vu KA, Stewart MG (2000) Structural reliability of concrete bridges including improved chloride-induced corrosion models. Struct Saf 22(4):313-333

Wallbank EJ (1989) The performance of concrete in bridges: a survey of 200 highway bridges. Her Majesty's Stationary Office, London
West RE, Himne WG (1985) Chloride profiles in salty concrete. National Association of Corrosion Engineers, Houston, pp 29-38 Zemajtis J (1998) Modeling the time to corrosion initiation for concretes with mineral admixtures and/or corrosion inhibitors in chloride laden environments. PhD dissertation, Virginia Polytechnic Institute and State Univ., Blacksburg 